\title{
A margem como expansão de territórios na arte: Colóquio Resistências e agenciamentos artísticos na virada dos anos 2000
}

\author{
Helena Wilhelm Eilers ${ }^{1}$
}

Resumo: Entre o final dos anos 1990 e o início dos anos 2000, a mobilização de artistas frente a um cenário pouco favorável à arte contemporânea brasileira culminou na criação de uma série de agenciamentos no circuito alternativo do Rio de Janeiro. Através de proposições pensadas e executadas pelos próprios artistas, foram abertos diversos espaços independentes e realizados projetos e exposições fora do meio tradicional de museus e galerias. Apesar de sua heterogeneidade, observa-se que grande parte das ações não buscava atuar como uma força contrária ao sistema institucional. Mais do que uma disputa de poder, foram encontradas maneiras de criar linhas de fuga que expandiam o território da arte a partir da criação. Destaca-se também no período o Colóquio Resistências, que ao discutir as várias possibilidades contidas na palavra "resistir", colocava em pauta a diversidade de ações que estavam acontecendo na prática.

Palavras-chave: arte contemporânea, circuito alternativo, agenciamentos, resistência

\section{The margin as an expansion of territories in art: Colloquium Resistances and artistic agencies at the turn of the $2000 \mathrm{~s}$}

\begin{abstract}
Between the end of the 1990s and the beginning of the 2000s, the mobilization of artists in the face of an unfavorable scenario for contemporary Brazilian art culminated in the creation of a series of agency in the alternative circuit of Rio de Janeiro. At that time several independent spaces were opened by the artists and exhibitions were produced outside traditional places, as museums and galleries. Despite the heterogeneity of the agencies, it is observed that most of them did not seek to act as a force to go against the institutional circuit. More than fighting an errant cultural system, what it seems to have was a way of creating lines of flight to expand the territory of art through them. In this article, it is also highlighted the Colloquium Resistance. The event discussed the various possibilities contained in the word "resist" and brought to the academic agenda some actions that were already happening in practice.
\end{abstract}

Keywords: contemporary art, alternative circuit, agencies, resistance

1 Mestre em Artes Visuais pelo Programa de Pós-Graduação em Artes Visuais da Escola de Belas Artes/UFRJ (2019) e jornalista especialista em Jornalismo Cultural. Atua como curadora independente e produtora cultural. Universidade Federal do Rio de Janeiro, UFRJ. E-mail: helenaweilweilers@gmail.com. ORCID: https://orcid.org/0000.-0002-3353985X. Lattes iD: http://lattes.cnpq.br/4295278197500212. Rio de Janeiro, Brasil 


\section{Entre fronteiras imprecisas, um território em movimento}

Qual a relação do pensamento com a terra?

Deleuze e Guattari ${ }^{1}$

Ao longo da história, não raras às vezes ressurge a questão: qual é o limite da arte? - pergunta com frequência acompanhada da afirmação de que a arte extrapolou seus limites. Seja rompendo a fronteira do bom senso para uns, ou do senso comum, para outros, a arte historicamente tem em sua essência a transgressão de um espaço pré-delimitado para se deslocar rumo a territórios inexplorados. Invade e ocupa espaços da vida, da política, da ciência, da tecnologia, da psicologia, da feitiçaria, da religião. Afeta outros campos de conhecimento e se deixa ser afetada por eles. Move-se de maneira irregular numa busca constante por abrir novos caminhos. Ao decorrer da história, tais limites são sempre mutáveis, assim como as fronteiras ou aquilo que tenta fazer barreira à sua expansão.

Com a licença poética da Geografia, de quem tomamos emprestado o importante conceito de território, e com o auxílio de Gilles Deleuze e Félix Guattari, procuramos neste artigo discutir o poder das margens no fazer artístico e sua capacidade de expandir territórios, ampliando seus limites e rompendo tais fronteiras. Tomamos como ponto de partida o Rio de Janeiro na transição dos anos 1990 para os anos 2000, alguns agenciamentos artísticos do período e o colóquio Resistências, realizado em 2002.

Antes de iniciar, entretanto, é necessário esclarecer que há diversas linhas teórico-conceituais nas quais a palavra margem e suas derivações podem ser utilizada. Neste texto, não nos referimos a elas em relação à condição socioeconômica dos artistas. Tampouco, fazemos referência ao local geográfico do qual a arte é oriunda, não tendo a intenção de trazer uma dicotomia periferia-centro no sentido literal. Tomamos como primária a ideia de alternativo à, ou seja, alternativo aos padrões tradicionais de se fazer exposição e à maneira de fazer circular a arte dentro do território.

Assim, a margem aqui referida entra em sintonia com a concepção de literatura marginal, movimento que também ocorreu no Rio de Janeiro, po- 
rém, na década de 1970. Como explica Cacaso², marginal era um termo usado para se referir àqueles que não conseguiam penetrar no mercado editorial e criavam formas de distribuição paralela. Mais tarde, a palavra também ganhou outras interpretações, agora referentes ao estilo de escrita e de vida. Deste modo, procura-se, na literatura e na arte, achar novos caminhos, como escreve o também poeta marginal Chacal':"É PROIBIDO PISAR NA GRAMA. O jeito é deitar e rolar ${ }^{4}$.

\section{Mapeando as margens do Rio}

Os anos 1990 são marcados por mudanças e contradições no âmbito cultural. Num rápido panorama, observa-se que com o início do governo em dois mandatos de Fernando Henrique Cardoso (1995-2002), o modelo neoliberal brasileiro se solidifica e a retração do Estado acontece em quase todas as áreas ${ }^{5}$. Com o destaque dado pelo governo às Leis de Incentivo, há um considerável aumento no investimento em cultura, entretanto, o mercado ganha poder de decisão sobre os projetos que serão desenvolvidos em âmbito nacional. Também nos anos 1990, acontece a propagação das exposições blockbusters no país, mais especificamente no eixo Rio-São Paulo. A vinda dessas mostras faz com que recordes de público em exposições de arte sejam atingidos no Brasil e exige que as instituições se profissionalizem. Por outro lado, acarreta em enormes gastos em projetos que não incentivam a produção de arte brasileira. Assim, entre galerias que abriam e as diversas que fechavam, os artistas procuravam novos espaços para a arte contemporânea ${ }^{6}$.

Mesmo que o circuito institucional se mostrasse pouco estimulante para a arte contemporânea brasileira - sem verba ou interesse em expor e finan-

2 Antonio Carlos de Brito (1944-1987), mais conhecido por seus amigos de geração como Cacaso, foi poeta, crítico literário, letrista e teórico da poesia marginal. Com formação filosófica, foi professor da PUC-RJ, onde lecionou Teoria da Literatura e Literatura Brasileira. Cf.: Brito: in Arêas, 1997, p. 12-13.

3 Ricardo de Carvalho Duarte (1951-). Poeta, letrista, criador do espaço CEP 20.000 (Centro de Experimentações Poéticas) em 1990, no Rio de Janeiro. Participante de diversas ações no circuito alternativo de arte e literatura.

4 Chacal, 2007. p. 214.

5 Rubim, 2007, p. 26.

6 Para um panorama da época, ver: Andrade, 2004. 
ciar a produção artística do período -, a produção plástica no Rio de Janeiro seguia em contínua efervescência. Entre o final dos anos 1990 e o início dos anos 2000, uma significativa emergência de proposições organizadas pelos artistas surge no país. Foram criados coletivos e realizadas ações coletivas, como exposições e eventos artísticos que transpassavam os muros dos museus e ocupavam lugares pouco convencionais para a arte. Do mesmo modo, foram abertas organizações que visavam facilitar a execução de projetos artísticos, tal como galerias gerenciadas pelos próprios artistas. Enquanto algumas seguiam um modelo mais tradicional, como a Gentil Carioca (2003-), outras inventavam outras formas de expor, como a Galeria do Poste de Arte Contemporânea (1997-?), em Niterói. Como bem definiu o artista e pesquisador Luís Andrade (1967-), em meio a tantas variáveis turvas do período, é possível dizer que a cidade se transformou em um "atraente tubo de ensaio" e as dificuldades que comumente atrasam determinados processos converteram-se em combustível para a sua realização ${ }^{7}$.

Cientes da impossibilidade de mapear em poucas páginas os diversos agenciamentos da época, buscou-se detalhar alguns deles com o objetivo de apresentar essa margem não como uma ação ou movimento único, mas como uma série de diferentes agrupamentos que se atravessavam e, juntos, compuseram e modificaram um território. A opção pelo uso do termo agenciamento não é fortuita - de origem deleuzo-guattariana, o agenciamento está relacionado à heterogeneidade dos corpos que conspiram para funcionar juntos ${ }^{8}$. Como descreve Deleuze, enquanto as estruturas estariam ligadas a condições de homogeneidade, o agenciamento "age em cofuncionamento", sendo ele a "simpatia", a "simbiose" 9 . Em um agenciamento não se perde a identidade própria, nem se adquire a identidade do outro, porém, também, não se ignora os demais nem lança sobre eles um olhar impessoal. Não se torna o louco, tampouco o doutor que o observa

\section{Andrade, 2004, p. 135.}

8 Assim como grande parte dos conceitos propostos por Deleuze e Guattari, o agenciamento permite uma série de leituras, assim como uma análise complexa, entretanto, uma definição similar do termo é dado por Guattari: "Agenciamento: noção mais ampla do que as de estrutura, sistema, forma etc. Um agenciamento comporta componentes heterogêneos, tanto de ordem biológica, quanto social, maquínica, gnosiológica, imaginativa." In: Guattari; Rolnik, 1986, p. 317. Uma definição mais ampla do uso em diversas obras dos pensadores é encontrada em: Zourabichvili: Goldstein, 2004.

9 Deleuze; Parnet, 1998, p. 43. 
com olhar científico asseptizado, explica Deleuze. Agenciar é, assim, "estar no meio" ${ }^{10}$.

São exemplos desses agenciamentos as exposições Orlândia (2001), Nova Orlândia (2001) e Grande Orlândia (2003), que reuniram cerca de 140 artistas num misto de mostra de arte, festa e manifestação política ${ }^{11}$. Sem patrocínio ou verba de produção, conseguiram agregar artistas com perfis distintos e de diferentes gerações em três exposições livres e não burocráticas, as quais tinham como objetivo contornar a falta de espaço para a arte contemporânea na cidade. Os eventos foram pensados e produzidas pelos artistas Márcia X (1959-2005), Ricardo Ventura (1962-), Bob N (1967-) e Elisa de Magalhães (1962-), contudo, sua realização só foi possível devido ao engajamento coletivo dos demais participantes ${ }^{12}$.

Os imóveis que receberam as Orlândias em nada lembravam o ambiente pretensiosamente neutro de museus e galerias: a primeira e a segunda edição aconteceram em uma casa da família de Ricardo Ventura, em Botafogo, que passava por um período de reformas. A última foi realizada em meio aos sobrados de São Cristóvão, também pertencentes à família do artista. Não houve estudo de iluminação, material informativo, catálogo ou convite formal. Cada artista era livre para apresentar o que quisesse, sem ter que passar por um crivo de curadoria. O resultado foi três mostras completamente informais, nas quais foram expostos trabalhos de poesia, fotografia, performance, vídeo, música, pintura, escultura, desenho e intervenção urbana.

Enquanto Orlândia e Nova Orlândia denunciavam a falta de apoio para a arte contemporânea abrindo espaço para ela, em Grande Orlândia - Artistas abaixo da Linha Vermelha, havia um motivo político mais pontual sobre o qual se manifestar. Na época, o então prefeito Cesar Maia tentava validar a construção do museu Guggenheim, no Píer Mauá. A obra era bastante controversa, rodeada de interesses obscuros, gastos exorbitantes e receita

10 Ibid., p. 44.

11 Para saber mais sobre as três Orlândias, sobre os artistas participantes e as obras, cf.: Eilers, 2019.

12 Apesar de Bob N ter participado apenas da primeira exposição, Orlândia, em 2001, teve relação direta com a concepção do conceito da mostra e escolha dos artistas. Elisa de Magalhães auxiliou na divulgação de Orlândia e a partir de Nova Orlândia passou a atuar diretamente na organização dos eventos. 
incerta $^{13}$. A questão passou a ser discutida pelo grupo ArtesVisuais_Políticas, formado por artistas, críticos e teóricos, que questionavam a maneira como as negociações vinham sendo feitas pelo prefeito, além de indagar sobre o uso do dinheiro público para a construção de um museu privado. Nesse contexto, foi proposta por Ricardo Ventura e Márcia X a Grande Orlândia, exposição que se tornou um espaço de resistência criativa da arte, um evento-manifesto ou, como sugere Suely Farhi ${ }^{14}$, uma manifesta.

Figura 1 Artistas participantes da Orlândia em matéria para o Jornal do Brasil. Foto: Divulgação. Fonte: ABREU, 2001, p. 5.

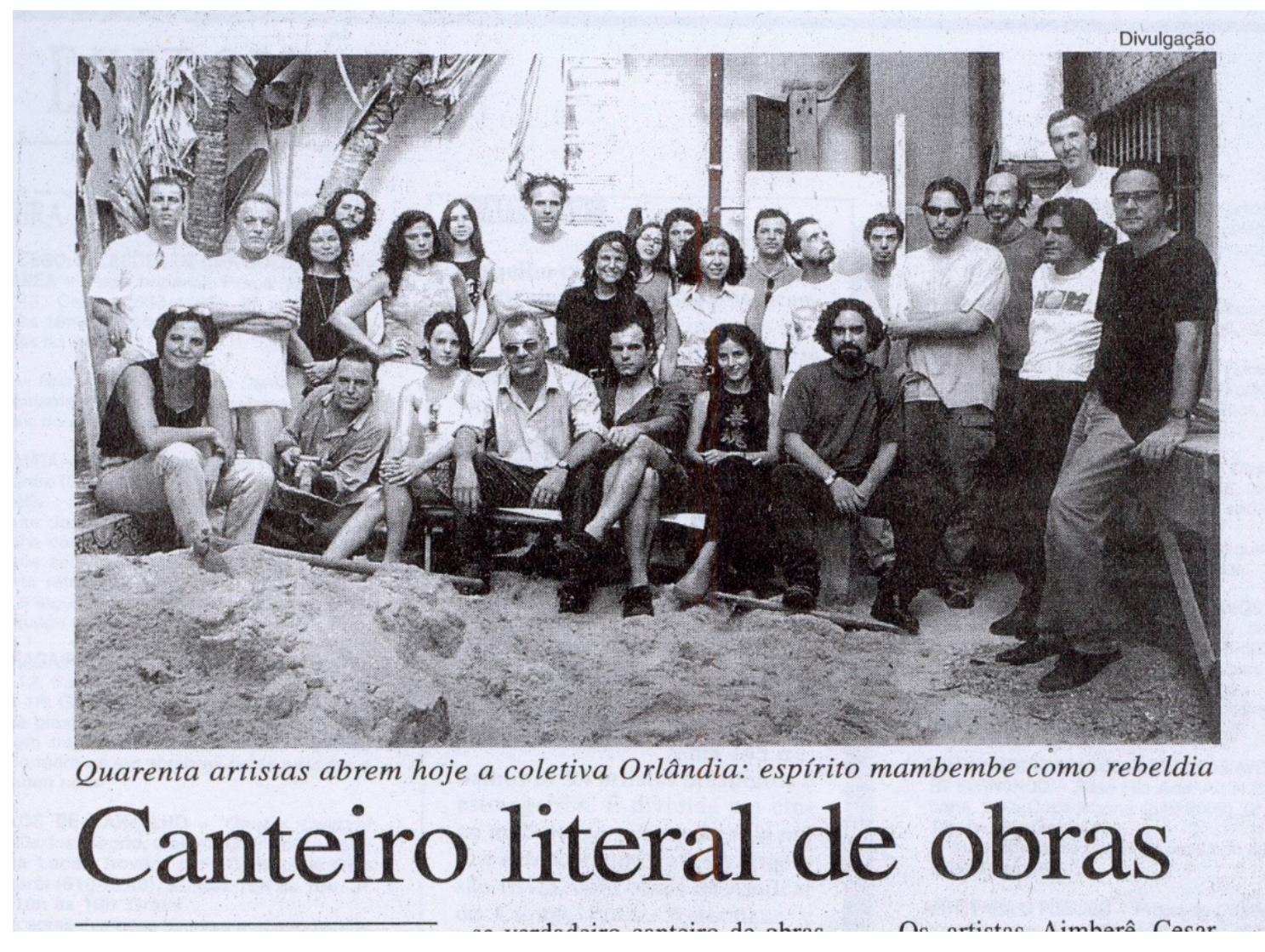

13 O município gastaria - só com os custos da construção - mais de US\$133 milhões, acrescidos de US\$800 mil anuais (por cinco anos), de quase US\$30 milhões em três parcelas para a recuperação do píer da Praça Mauá e valores dos impostos sobre a renda e Operações Financeiras (IOF), ademais dos incidentes sobre a operação do museu. Além disso, o município se comprometeu a dar garantia, por dez anos, dos déficits operacionais até o valor de US\$12 milhões. Esses dados foram publicados em: http://agenciabrasil. ebc.com.br/geral/noticia/

2015-11/ex-prefeito-e-fundacao-guggenheim-condenados-restituir-municipio-do-rio. Acessado em: 24 fev. 2019.

14 Entrevista concedida por e-mail em 25 de maio de 2019. Publicada em: Eilers, 2019, Vol. II, p. 174. 
Figura 2

Vista externa do imóvel em São Cristóvão e intervenção realizada por Ricardo Ventura. Grande Orlândia, 2003. Foto: acervo de Ricardo Ventura.

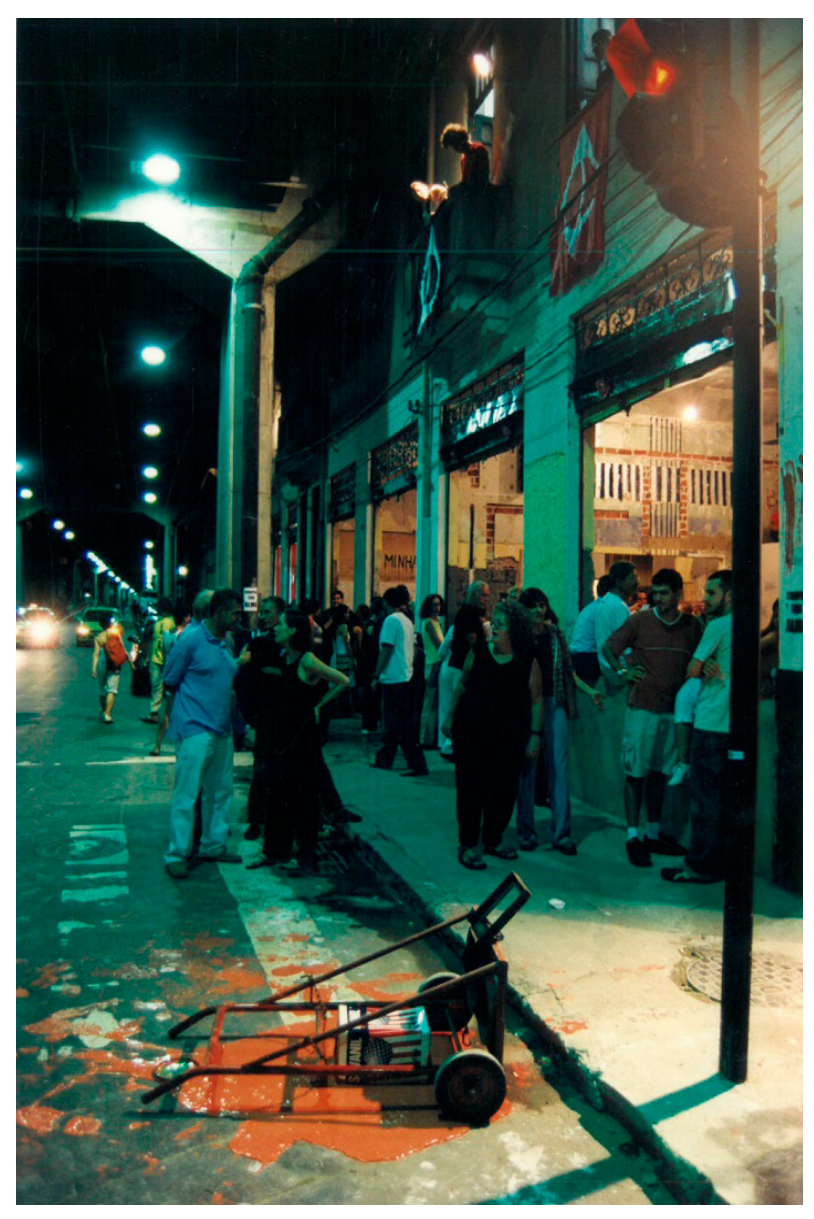

Assim como outras proposições realizadas na época, as Orlândias se apropriaram de táticas as quais permitiram que elas agissem num território considerado por muitos artistas como insuficiente ${ }^{15}$. As táticas, são para Michel de Certeau, as astúcias, o saber aproveitar as oportunidades que surgem. É a arte daqueles que não detêm o poder. Com as táticas, Certeau enfatiza processos criadores que têm lugar pela apropriação e uso de espaços, materiais e repertórios simbólicos. Mais do que instituir um lugar próprio, é saber jogar com o terreno que lhe é imposto, é criar e agir na possibilidade do lugar e do momento,

a tática é o "movimento dentro do campo de visão do inimigo" e no espaço por ele controlado. Ela não tem, portanto, a possibilidade de dar a si mesma um projeto global nem totalizar o adversário num espaço distinto, visível e objetivável. Ela opera golpe por golpe, lance por lance. Aproveita as ocasiões e delas depende ${ }^{16}$.

15 Considera-se aqui os artistas participantes das exposições. Quarenta deles foram entrevistados e o resultado foi publicado em Eilers, 2019, Vol. II.

16 Certeau, 2014, p. 95. 
As Orlândias, para que pudessem ser produzidas, se apropriaram de uma série de ferramentas que fazem parte do sistema da arte: espaço expositivo, verba, mídia e redes de contato. Na falta de um museu ou galeria, entretanto, buscam um imóvel vago, que não traria praticamente custos, como aconteceu com a casa de Botafogo e com as lojas de São Cristóvão. Da mesma maneira, os artistas usam seus conhecimentos para fazer da mídia um canal de expansão: enquanto o material de divulgação ficou por conta do artista Walter Guerra (1954-), que tinha um escritório de design na época, a divulgação foi feita por Elisa de Magalhães, que tem formação em jornalismo e fez a ponte com jornais e revistas. A verba inicial para que a exposição pudesse ser realizada veio da venda de obras de Ricardo Ventura e Márcia X, além disso, durante e depois das exposições outras obras foram comercializadas ou apresentadas em lugares institucionalizados

Ao serem realizadas, as Orlândias não buscavam se isolar em um outro circuito, fechar uma estrutura. Pelo contrário, através do agenciamento de artistas, críticos, curadores, mídia e colecionadores procuravam expandir essa rede. As Orlândias, assim como outras ações realizadas no período, abrem brechas no circuito institucional e fazem aquele território restrito se expandir através da criação, do alargamento de suas margens.

Com um tom mais anárquico, foi realizado durante um ano o projeto Zona Franca (2001), na Fundição Progresso, no centro do Rio de Janeiro. Organizado por artistas como Alexandre Vogler (1973-), Adriano Melhem (1972), Aimberê Cesar (1958-2016), Ducha (1977-), Guga Ferraz (1974-) e Roosivelt Pinheiro (1964-), tratava-se de uma ocupação artística independente, considerada pelos organizadores como um evento sem curadoria e sem regras, ou, como define Ducha, "um cabaré aberto" ${ }^{17}$. Alexandre Vogler, explica que eles convidavam outros artistas alertando que "tudo o que você não pode fazer em uma galeria, você pode fazer no Zona Franca", o que fez com que a ocupação resultasse em "uma grande desordem de anarquistas apresentando trabalhos aleatoriamente." ${ }^{18}$. Guga Ferraz, que havia recém se formado em Belas Artes, concorda:

era uma política de abertura de espaço, uma reunião de amigos onde todo mundo se ajudava. Ainda não tinha a Gentil Carioca, a galeria Arthur Fidalgo trabalhava com

17 Entrevista concedida por e-mail e telefone em 16 abr. 2019. Publicada em: Eilers, 2019, Vol. II, p. 110.

18 Monachesi, 2003, capa. 
artistas que já tinham um campo, como [Artur] Barrio e Cildo [Meireles]. Naquele tempo não tinha um mercado de arte, tínhamos que inventar o mercado para poder entrar dentro ${ }^{19}$.

Os encontros do Zona Franca aconteciam toda segunda-feira e não eram voltados exclusivamente à exposição da arte. Muitas vezes, como relatou Ericson Pires (1971-2012), nada estava acontecendo, a não ser "a disposição do espaço como lugar de acontecimentos: conversas, articulações, trocas, rompendo com a obrigatoriedade linear de um evento de arte ou de entretenimento" ${ }^{20}$. Lá, havia liberdade para apresentar qualquer trabalho que não fosse aceito em instituições, o que acarretava alterações constantes na estrutura. Em uma ocasião, lembra Alexandre Vogler em entrevista à Thiago Fernandes, Carlos Eduardo Feferman (197?-) quebrou uma parede durante a exibição de um filme, em outra Sandrigo Monteiro (197?-) realizou uma escultura presa num pneu, a qual ateou fogo ${ }^{21}$. Guga Ferraz vê no Zona Franca o processo mais próximo da anarquia que vivenciou:

Houve um momento em que começamos a desafiar o nosso limite. Uma vez, quando não havia nada acontecendo, o Ronald Duarte começou a rodar uma corrente e dar linha, quase pegando na galera, e ele continuava rodando aquilo. Então começamos a tacar latinhas de cerveja nele, a jogar várias coisas nele, até ele parar. Nós quase nos feríamos, o Ducha quebrava tudo, eu quebrava tudo, ficava bêbado, esquecia de tudo. Não fomos expulsos da Fundição Progresso, mas ficaram felizes quando falamos que não ia mais acontecer o Zona Franca ${ }^{22}$.

A atuação de Vogler junto a projetos coletivos não era recente. O Atrocidades Maravilhosas, por exemplo, começou como um desdobramento de sua pesquisa mestrado e acabou reunindo 20 artistas para colar inúmeros lambes pelo Rio de Janeiro. Junto a membros do Rrradial, Vogler realizou diversas vezes o "fumacê do descarrego", no qual um defumador era instalado em cima de um caminhão que corria pela cidade para dar um banho de descarrego. Em uma entrevista de 2003, o artista afirma: "eu faço meu circuito, não preciso esperar convite nem babar ovo para ninguém" ${ }^{23}$.

19 Entrevista realizada na casa do artista, no Rio de Janeiro, em 7 set. 2018.

20 Fernandes, 2018, p. 180.

21 Idem.

22 Fernandes, 2018, p. 181.

23 Monachesi, op.cit. 


\section{Coluna by Guga Ferraz}

Figura 3

Performance Colu-

na, de Guga Ferraz, apresentada no

Zona Franca (2001) e em Orlândia

(2001). Foto: still

do filme A (re)volta do Zona Franca.

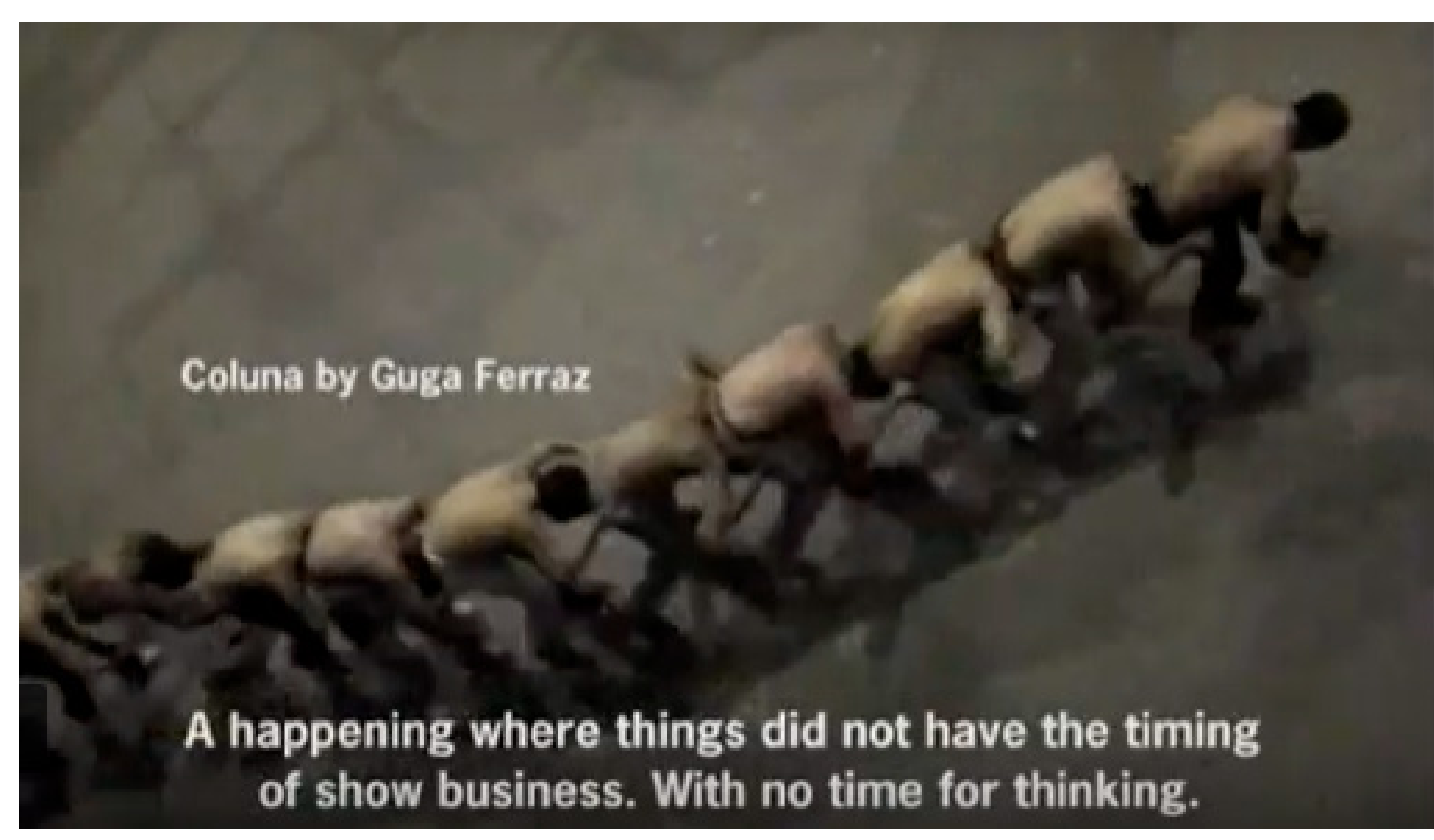

Uma característica importante de ressaltar é que alguns desses agenciamentos, apesar de acontecerem em um espaço alternativo, não impossibilitava os artistas de buscar parcerias, como por exemplo, financiamentos públicos e privados que permitissem a viabilização dos projetos. É por tal razão que o artista e pesquisador Newton Goto (1970-) também se refere a estes agenciamentos como autodependentes. O termo provém do conceito usado pelo cineasta alemão Werner Herzog como uma alternativa para diferenciar do cinema independente, pois, segundo Herzog:

ao contrário de imaginar esse âmbito produtivo como algo desvinculado de parcerias e relações - independente -, o cineasta vê esse campo de atuação como algo que fundamentalmente depende do próprio autor para existir, inclusive nas articulações de parcerias ${ }^{24}$.

Um espaço que soube se beneficiar dessa relação entre arte, mercado, patrocínios e editais foi o AGORA - Agência de Organismo Artísticos (19992003), criado por Ricardo Basbaum (1961-), Eduardo Coimbra (1955-) e Raul Mourão (1967-). Aberto inicialmente na Fundição Progresso, na Lapa, abrigava ateliês, espaço para exposição, cursos e bar. Apesar de não se considerarem produtores culturais, mas sim, "artistas criando novas oportunidades de trabalho, para nós mesmos e para o meio da arte como 
um todo", foram responsáveis por viabilizar uma série de eventos artísticos, como, por exemplo, a exposição Love's House ${ }^{25}$. Com patrocínio da RioArte e Furnas, reuniu treze artistas num local que era um misto de motel e de pensão, usado como moradia, mas também como local para rápidos encontros amorosos. Durante os dias da exposição, o hotel seguiu funcionando normalmente na Lapa ${ }^{26}$. Durante dois anos a AGORA trabalhou em parceria com o artista Helmut Batista (1964-), formando o Espaço AGORA/Capacete, localizado Rua Joaquim Silva, também na Lapa. Em 2002, a parceria foi desfeita e ambas seguiram atuando como agências independentes.

A trajetória de Basbaum, Coimbra e Mourão junto a grupos e iniciativas que questionam o circuito artístico, entretanto, é mais antiga. Basbaum foi

Figura 4 Artistas participantes da exposição Love's House. Fotografia de Fabio Seixo. Fonte: Name, Daniela, 2002, p. 2.

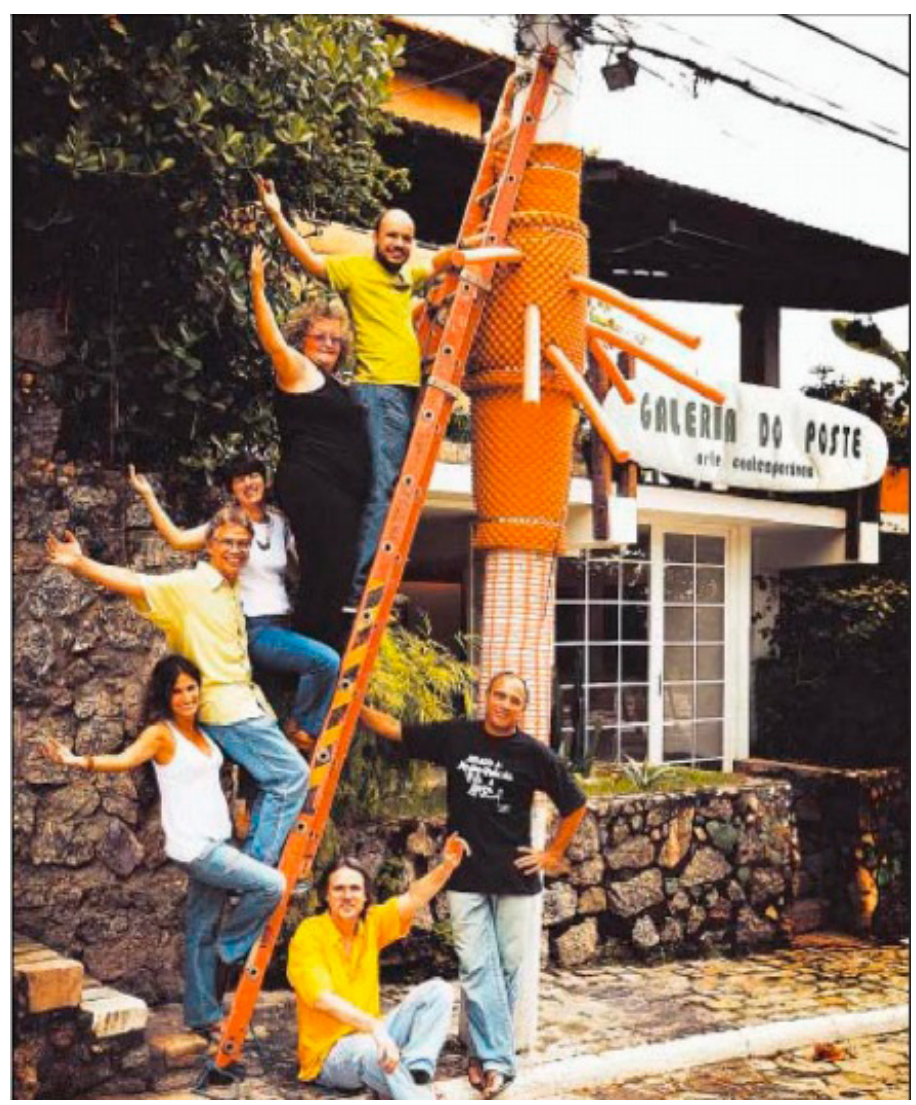

\section{Osório, 2000, p. 14.}

26 A exposição ocorreu em março de 2002 com os artistas: Brígida Baltar (1959-), Carla Guagliardi (1956-), Eduardo Coimbra, Fernanda Gomes (1960-), João Modé (1961-), Laura Lima, Lívia Flores (1959-), Marcos Chaves (1961-), Raul Mourão e Ricardo Basbaum, Ricardo Becker (1961-), Tatiana Grinberg (1967-) e o coletivo Chelpa Ferro, formado por Luiz Zerbini (1959-), Barrão (1959-) e Sérgio Mekler (1953-). A mostra aconteceu simultaneamente à XXV Bienal de São Paulo. Cada artista ocupou um quarto do terceiro andar do hotel que ficava ao lado da sede do Agora. 
Figura 5

Ricardo Pimenta e outros artistas em frente à Galeria do Poste, 2003. Fotografia: Leo Aversa. Fonte: Name, Daniela, 2005, p. 2.

um dos criadores do grupo $A$ Moreninha e, junto com Coimbra, participou ativamente das atividades do grupo Visorama (1989-1994), formado por artistas contemporâneos do Rio de Janeiro. Os dois grupos tinham uma visão crítica do circuito artístico e do o comercialismo voraz do período, atuando de maneira a buscar mais autonomia e espaço para os artistas. Mais tarde, os dois lançaram junto a Mourão a Revista Item (1995-2003), que foi editada pela Agora, com patrocínio da Petrobrás ${ }^{27}$.

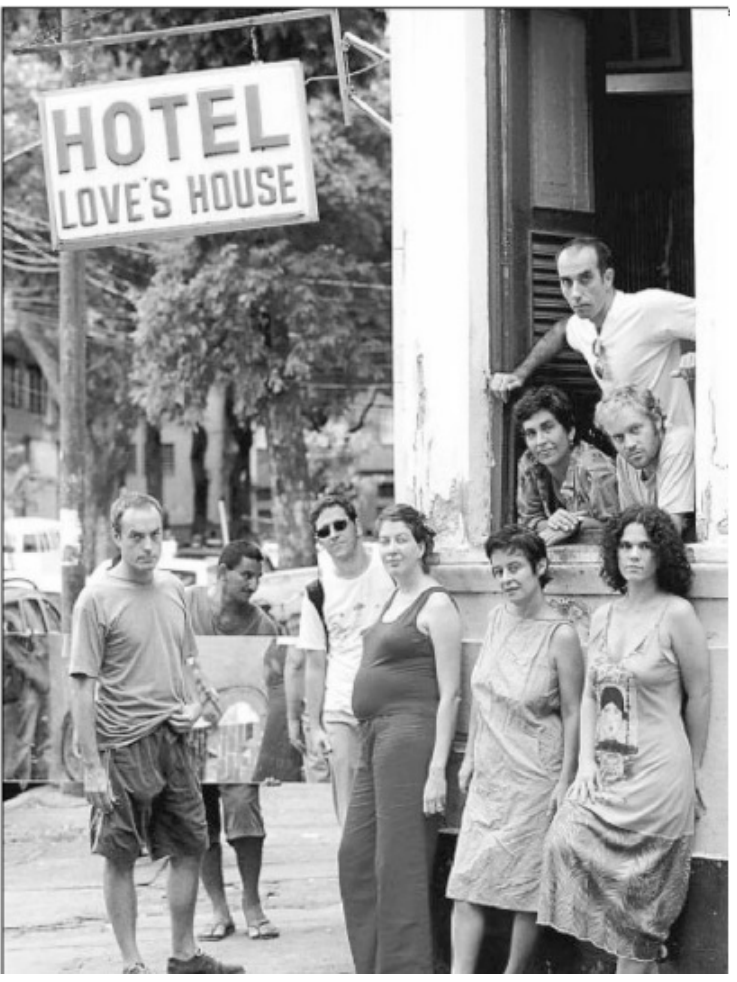

Para finalizar os exemplos com outros modelos de agenciamentos, citamos duas galerias: Galeria A Gentil Carioca e a Galeria do Poste de Arte Contemporânea. A Gentil Carioca foi aberta em 2003 no centro do Rio de Janeiro, onde permanece até hoje. Para o artista Ernesto Neto (1964-), um dos fundadores, a necessidade de um artista gerenciar um espaço surge quando o circuito não tem condições de absorver o que está acontecendo, seja por escassez de mercado ou visão conservadora. ${ }^{28}$ Ele se uniu com os também artistas Laura Lima (1971-), Márcio Botner (1970-) e Franklin 
Cassaro (1962-) para criar a galeria, que até hoje se mantém ativa no centro do Rio de Janeiro. Sobre ser também empresário, Neto comenta: “É um momento em que o artista está atuando em vários braços. Ele não só cria a obra de arte, como agencia, é galerista, curador e crítico. Ele começa a permear todo o circuito artístico"29.

A Galeria do Poste de Arte Contemporânea, por sua vez, era um espaço que conciliava tanto a característica de intervenção na cidade como de espaço autogerido. Foi idealizada pelo artista Ricardo Pimenta (1957-) e ficava localizada em um poste em frente ao seu ateliê, em Niterói, que foi ressignificado como um local para exposição de arte. Tida como a galeria que nunca fecha, convidava mensalmente um artista para expor e a programação envolvia arte, música e poesia. A interação com os passantes era inevitável e logo o espaço passou a servir também como ponto de encontro para a comunidade, agrupando em seus eventos cerca de 200 pessoas que se reuniam com música e festas ${ }^{30}$. A maneira irônica como cria uma ligação com o institucional é indicada pelo nome, Galeria do Poste de Arte Contemporânea, um paralelo feito entre o então recém-inaugurado Museu de Arte Contemporânea de Niterói (1996) e a famosa galeria Thomas Cohn: "Se ele [MAC] era de arte contemporânea, se a galeria do Thomas [Cohn] também o era, o poste também haveria de ser"31.

Ressaltamos que muitas outras movimentações artísticas aconteciam no período e que o objetivo dessas escolhas foi o de exemplificar por meio de modelos distintos de atuação. Apesar da pluralidade dos agenciamentos, é possível pontuar duas características em comum encontradas neles: 1) busca por lugares externos às instituições e 2) gestão de espaços de artes feita pelos próprios artistas. Além dessas, é interessante observar que grande parte desses agenciamentos não intentava atuar como uma força a se sobrepor ao institucional ou ir contra ele. Mais do que lutar contra um sistema cultural errante, o que parece ter acontecido nos anos 1990 e se consolidado nos anos 2000 foi uma maneira de abrir brechas nesse sistema, fissurar aquele espaço-tempo, compreender que as paredes do museu eram pequenas se comparadas às ruas e aos demais espaços que poderiam ser criados, geridos ou ocupados. Assim, tais agenciamentos criavam no-

29 Idem.

30 Bedran, 2018.

31 Disponível em: http://galeriadoposterio.blogspot.com/. Acessado em: 13 out 2018. 
vos territórios através da expansão daquele que estava dado, não buscando destruí-lo ou ignorá-lo, mas ampliá-los através da criação.

\section{Re-exististir e criar: o colóquio Resistências}

Nesse mesmo período em que a margem se movimentava em uma pluralidade de ações, foi realizado no Rio de Janeiro o colóquio Resistências (2002). Tendo como tese principal de que a resistência pode ser um conceito afirmativo, procurou, através de diferentes linhas de pensamentos filosóficos, repensar o uso da palavra, trazendo em suas discussões a ideia de que a resistência não deveria ser vista apenas como um movimento de oposição (resistir a ou resistir contra) ou ter como objetivo suportar algo, mas sim, ser uma afirmação de um modo de existência, tratando-se, dessa forma, de uma re-existência.

O evento foi realizado no CineBR Odeon, proposto pela Universidade Federal do Rio de Janeiro e pelo Collège International de Philosophie (Paris) e organizado por Tatiana Roque (1970-). Contou, ainda, com a presença do filósofo Alain Badiou. Roque afirmava que o objetivo do simpósio era "subverter a polaridade entre pensamento e ação, ao reunir intelectuais, artistas e militantes na construção de sentidos das resistências na arte contemporânea"32. Hoje é possível fazer uma leitura de que, ao mesmo tempo em que a organização do evento propunha sair do mundo puramente intelectual para a ação, de certa forma, conseguiu trazer para o debate teórico algo que já estava acontecendo na prática. Assim, o colóquio discutia as maneiras de resistir que, em parte, já se concretizavam em forma de ações diversas.

Para Roque, a resistência não necessariamente buscaria atuar como força contrária à atual ou então substituí-la ${ }^{33}$. Através da argumentação etimológica, a pesquisadora destaca e analisa o prefixo "re" que, se voltando a ele mesmo, apontaria para a não necessidade de se acrescentar aquilo contra o que a resistência se volta, sendo assim, não demandava de opositores ou inimigos. Com isso, ela levanta a possibilidade de pensar no conceito 
de resistência como independente daquilo a que ela resiste, mas como um processo que está em curso, anterior ao fato ao qual resistir. Resistir seria assim "insistir em estar":

Na ideia de resistência há, antes de tudo, o prefixo re que aponta para uma duplicação, "outra vez", um desdobramento, uma dobra, "outra vez". Do que o segue, lemos um substantivo derivado do verbo sistere: parar permanecer, ficar, ficar de pé, estar presente. A esse verbo se associa também a stantia da palavra resistência que invoca a estadia, ideia perfeitamente expressa pela transitoriedade do verbo estar, uma das preciosas singularidades do português. Até aqui, portanto, resistir é insistir em estar - em permanecer, em ficar de pé". ${ }^{34}$

Se voltando para a própria existência, ou para a própria stantia, haveria, para Roque, uma duplicação, uma dobra: "Trata-se da dobra da existência, do estar pleno; pleno de seus desdobramentos e de sua série (...). A resistência é a dobra da existência", argumenta ${ }^{35}$. Essa dobra, de origem foucaultiana, surge da ideia de dobrar uma linha de força para que ela atinja a si a mesma. Em um campo formado por relações de poder, controlado e vigiado, modos de existência são constituídos de acordo como a linha é dobrada, modos de vida são criados $^{36}$. Assim, a dobra na resistência é re-existir.

Junto com Roque, Ericson Pires participou ativamente do colóquio, escrevendo textos para o evento, que se desdobraram em artigos sobre o tema. Artista, pesquisador, poeta e militante nas artes, discorreu sobre a resistência como ação e como afirmação.

Re-insistências. Resistência. Existir. Re-existir: sempre no possível, sempre nas possibilidades. Romper, continuar. Ir além do óbvio, do sim domesticado, do clichê assumido como real. Inaugurar sempre a possibilidade, novas possibilidades, a possibilidade do outro. Insistir. Re-insistir ${ }^{37}$.

Nessa busca de ativação do corpo e do intelecto como força de resistência, Pires participou ativamente do desenvolvimento do cenário artístico que se construía paralelamente ao meio institucional: foi um dos fundadores do espaço autônomo CEP 20.000, ao lado de Guilherme Zarvos (1957-) e Ricardo Chacal, foi criador do coletivo musical HAPAX (2001-?), e parti-

34 Idem.

35 Ibid., p. 26

36 Deleuze, 1990, p.75.

37 Pires, 2003a, p. 109. 
cipante de uma série de outros grupos. Para ele não se tratava de pensar nos grupos e ações que surgiram no início dos anos dois mil apenas como reações a um contexto desfavorável às artes. Apesar de enxergar um "esvaziamento cultural e financeiro" e uma ausência quase total de políticas públicas, o autor considerava que a proliferação de ações e agentes nos anos 1990 iria além da reação, estando muito mais ligada a "modos de concepção e a políticas de afirmação"38. A resistência se aproximaria mais para um modo de ser, não agindo de forma unilateral ou na negatividade, mas numa ação criativa e afirmativa, a qual ele convoca os artistas a seguir:

Coletivos, grupos, outros circuitos, espaços públicos, atacar/saquear meios métodos de financiamento, utilizar o mercado problematizando-o, arrancando bolsas de financiamento, construindo autonomia, independência, levar sempre ao limite: criar formas de ação e relação dentro do tal mercado da arte, implodir ${ }^{39}$.

Finalizando, Pires resume:

Resistência: Escapar aos clichês, sacar os limites, articular as redes, romper os círculos viciosos do proselitismo de mercado, destruir os jabás e a corrida corporativa dos grupelhos da política pública e privada. Afirmar o outro, o público, a geral, o carnaval das experiências, a cria-ação de redes de coletivos que criam movimentos, que potencializam resistências. Criar. Resistir agora ${ }^{40}$.

Criar, resistir, afirmar, sair do clichê. O contexto das forças afirmativas nasce com o pensamento nietzschiano da divisão entre as forças que agem (ativas) e as que reagem (negativas). Enquanto as primeiras somam e criam, as segundas agem por meio da subtração, diminuindo da força ativa o que pode enfraquecê-las e trabalhando por meio da dominação, controle e da adaptação. A força negativa é a força dos fracos. Para Nietzsche, segundo interpreta Deleuze, se nessa relação de forças há uma vitória da reação e das forças do negativo, essa é também a vitória do niilismo: "Quando o niilismo triunfa, então e só então a vontade de poder deixa de querer dizer "criar", passa-se a querer o poder, desejar dominar"41.

Nesse campo de forças ativas e reativas que emana o poder afirmativo ou

38 Pires, 2007, p. 23.

39 Pires, 2003, p. 25.

40 Pires, 2003, p. 25.

41 Deleuze, 2007, p. 26. 
negativo. Enquanto o primeiro está relacionado ao criar, à potentia (potência) e o outro está fadado ao desejo de dominar, reprimir, tirar a potestas (poder). Nessa relação entre criação, resistência e poder afirmativo, Deleuze declara: resistir é criar ${ }^{42}$. O autor explica que, assim como os filósofos criam conceitos, pintores, músicos, matemáticos, biólogos e cientistas resistem e exercem uma forma de resistência através de suas criações. Criar estaria, então, relacionado à produção de novas maneiras de viver e de pensar, inventar novas formas de ser e de estar no mundo, construir novos territórios.

\section{A expansões da margem}

Dentro do contexto de resistência é possível fazer uma leitura das proposições artísticas anteriormente citadas como linhas de fuga ${ }^{43}$, que rompem com o território existente, não o tomando como única possibilidade, mas projetando alternativas que pressionem a criação de novas situações em relação ao sistema estabelecido. Essas ações coletivas escapam a um campo social estratificado e atuam como força de resistência menos ligada à contradição (ao ir contra), e mais à criação de processos que convergiam num novo território. Sem impor uma força contrária, que acarretaria numa disputa dentro de um campo de poder, criam trajetos alternativos, que borram os limites entre o meio institucional e a margem, os mantendo sempre em contato, fazendo com que os dois sejam afetados e ambos se expandam.

Esse movimento de criação, de resistência afirmativa, faz com que o território esteja em um movimento constante de construção e desconstrução, destruindo o que está dado e inerte e rompendo um círculo inicialmente fechado, abrindo-o para o Universo, para que novas forças, do acaso e do pensamento, possam nele atuar ${ }^{44}$. Só através da desterritorialização abre-se espaço para o pensamento e para a criação. Os artistas que, individual ou coletivamente, atuavam nesse cenário marginal dos anos 1990-2000 criavam para eles novas subjetividades e desafios. Apesar do contato constante com o meio institucional, eles não destruíam ou diminuíam um espaço existente, mas o viam como um território a ser expandido pela força 
criativa, abrindo espaço para eles, assim como para outros.

Acredita-se também que, frente ao atual cenário político-cultural brasileiro, seja importante resgatar movimentações que, de forma tática, se apropriaram de diversos meios para expandir as bordas do experimental e do espaço da arte. Por mais que as dificuldades encontradas pelos artistas hoje difiram das da época aqui trabalhada, acreditamos que discutir problemas do passado sirva como um ponto de conexão e reflexão com o presente. Afinal, perguntas como: qual o limite da arte ou o que pode a arte? vão se transfigurando ao longo da história. Sabe-se, porém, que, independentemente do espaço-tempo, a arte afeta e é afetada por outros eventos e outras disciplinas, e, por meio desses atravessamentos tem a possibilidade infiltrar-se e criar novas subjetividades.

\section{Referências}

ANDRADE, L. Rio $40^{\circ}$ Fahrenheit. Revista Concinnitas. n. 5. Rio de Janeiro: Instituto de Artes/UERJ. p. 127-149, 2004.

ABREU, Gilberto de. Canteiro literal de obras. Jornal do Brasil, Rio de Janeiro, 5 maio 2001. Caderno B, p. 5

BASBAUM, R. E Agora? Revista Arte \& Ensaios. n. 9. Rio de Janeiro: Escola de Belas Artes/UFRJ. 2002. Disponível em: https://www.ppgav.eba.ufrj.br/ wp-content/uploads/2012/01/E-agora-Ricardo-Basbaum.pdf. Acessado em: 19 out. 2018

BEDRAN, Laura Martini. Galeria do Poste Arte Contemporânea. Estudo Etnográfico sobre arte e espaço Urbano. Revista Arte \& Ensaios. Rio de Janeiro: Escola de Belas Artes/UFRJ. 2002. Disponível em: https://www.ppgav. eba.ufrj.br/wp-content/uploads/2012/01/Galeria-do-Poste-Arte-Contempor\%C3\%A2nea-estudo-etnogr\%C3\%A1fico-sobre-arte-e-inventividade-no-espa\%C3\%A7o-urbano-Laura-Martini-Bedran.pdf. Acessado em: 19 out. 2018.

BRITO, A. C. Não quero prosa/Cacaso. In: ARÊAS, Vilma (Org.). Não quero prosa. Campinas: Editora da UNICAMP, 1997.

CERTEAU, M. de. A invenção do cotidiano: 1 . Artes de fazer. $22^{\mathrm{a}}$ ed. Petrópolis, RJ: Vozes, 2014.

CHACAL. Belvedere [1971-2007]. São Paulo: Cosac Naify, 2007.

DELEUZE, G. Nietzsche. Lisboa: Edições, v. 70, 2007.

DELEUZE, G.; BACON, F. O abecedário de Gilles Deleuze. 1988. Transcri- 
ção integral do vídeo para fins exclusivamente didáticos. Disponível em: www.docstoc.com/search/gilles-deleuze. Acessado em: 15 jun. 2018.

DELEUZE, G.; GUATTARI, F. Mil Platôs: capitalismo e esquizofrenia. Vol.5. Rio de Janeiro: Ed. 34, 1997.

DELEUZE, G.; PARNET, C. Diálogos. Tradução de E. A. Ribeiro. São Paulo: Editora Escuta, 1998.

GUATTARI, F; ROLNIK, S. Micropolítica: cartografias do desejo. Petrópolis, RJ: Vozes, 1996.

EILERS, H. W. Orlândias: Táticas para abertura de brechas e deslocamentos no circuito institucional. Dissertação (Mestrado em Artes Visuais). Programa de Pós-graduação em Artes Visuais, Universidade Federal do Rio de Janeiro (PPGAV/UFRJ). Rio de Janeiro, 2019.

FERNANDES, T. S. M. Lugares do Experimental no Rio de Janeiro: da Década de 1970 ao Zona Franca. Revista Concinnitas, v. 1, n. 32, p. 162-190, 2018. MONACHESI, J. A explosão do a(r)tivismo. Folha de São Paulo, São Paulo, 6 maio 2003. Caderno Mais!, capa.

NAME, D. Love's House. O Globo, Rio de Janeiro, 27 de março de 2002. Segundo Caderno, p. 2.

NAME, D. As portas se abrem para as artes. O Globo, Rio de Janeiro, 6 de fevereiro de 2005. Segundo Caderno, p. 2.

NUNES, K. Espaços autônomos de arte contemporânea. Rio de Janeiro: Editora Circuito, 2013.

OSÓRIO, L. C. Arte encontra lugar na Lapa. O Globo, Rio de Janeiro, 13 de maio de 2000, Segundo Caderno.

PIRES, E. Cidade ocupada. Rio de Janeiro: Aeroplano Editora, 2007.

PIRES, E. Riscos de arte, resistência. Revista Glob(A.L.) Brasil. Número (0), janeiro de 2003. p. 25. Disponível em: <https://issuu.com/globalbrasil/ docs/revista_global_0>. Acessado em: 9 ago. 2018.

PIRES, E. 12 proposições: resistência, corpo, ação - estratégias e forças na produção plástica atual. Revista Lugar Comum: Estudos de Mídia, Cultura e Democracia, Rio de Janeiro, v. 17, $2003 a$.

ROQUE, Tatiana. Resistências. Revista Glob(A.L.) Brasil. Número (0), janeiro de 2003. p. 24-25. Disponível em: https://issuu.com/globalbrasil/ docs/revista_global_0. Acessado em: 9 ago. 2018.

ROQUE, Tatiana. Resistir a quê? Ou melhor, resistir o quê. Revista Lugar Comum: Estudos de Mídia, Cultura e Democracia, Rio de Janeiro, v. 17, 2003a.

RUBIM, Antonio Albino Canelas. Políticas culturais no Brasil: tristes tradi- 
ções, enormes desafios. In: BARBALHO, Alexandre; RUBIM, Antonio Albino Canelas. Políticas culturais no Brasil. Salvador: Edufba, v. 1, 2007. VENTURA, Mauro. As portas se abrem para as artes. 0 Globo, Rio de Janeiro, Segundo Caderno, p. 8, 4 de janeiro de 2005.

ZOURABICHVILI, F.; GOLDSTEIN, V. O vocabulário de Deleuze. Rio de Janeiro: Relume Dumará, 2004. 